\title{
Prevalence of porcine cysticercosis in Bareilly, Northern India
}

\author{
B. C. Saravanan ${ }^{1}$, H. V. Manjunathachar ${ }^{1}$, A. K. Tewari ${ }^{1}$, S. C. Gupta ${ }^{1}$, K. Karthik ${ }^{2}$, P. Tamilmahan ${ }^{3}$ and N. R. Sudhakar $^{1}$ \\ 1. Division of Parasitology, Indian Veterinary Research Institute, Izatnagar-243122, Uttar Pradesh, India; \\ 2. Division of Bacteriology and Mycology, Indian Veterinary Research Institute, Izatnagar-243122, Uttar Pradesh, India; \\ 3. Division of Surgery, Indian Veterinary Research Institute, Izatnagar-243122, Uttar Pradesh, India \\ Corresponding author: B. C. Saravanan, email: drbcsaravanan@gmail.com, Tel.: +91-581-440368 \\ Received: 15-03-2014, Revised: 05-04-2014, Accepted: 08-04-2014, Published online: 03-05-2014
}

doi: $10.14202 /$ vetworld.2014.281-283

How to cite this article: Saravanan BC, Manjunathachar HV, Tewari AK, Gupta SC, Karthik K, Tamilmahan P and Sudhakar NR (2014) Prevalence of porcine cysticercosis in Bareilly, Northern India, Veterinary World 7(5): 281-283.

\begin{abstract}
Aim: The objective of this study was to investigate the prevalence of Taenia solium cysticercosis in pigs slaughtered at makeshift houses in Bareilly, Northern India.

Materials and Methods: Local makeshift slaughter houses were visited weekly in Bareilly to explore the prevalence of the porcine cysticercosis in this area. 175 pigs were screened for cysticercosis and prevalence was correlated to age, sex and breed of pigs.
\end{abstract}

Results: A total of 175 pigs were examined for cysticercosis out of which $9(5.14 \%)$ were found positive for porcine cysticercosis. Sex-wise prevalence of this infection in male and female was recorded as 4.82\% (4/83) and 5.43\% (5/92), respectively. The infection was higher (5.34\%) in the young age group of 1-12 months as compared to the older stocks of $13-24$ months of age group (4.54\%). Prevalence of porcine cysticercosis was relatively higher in cross bred pigs $(5.88 \%, 6 / 102)$ than in the non-descript local breed of pigs $(4.11 \%, 3 / 73)$.

Conclusion: The present study reveals that T. solium cysticerci infection is prevalent in swine population of Bareilly. Keeping in view the zoonotic importance, strict hygienic measures need to be undertaken for prevention of human infection.

Keywords: cysticercosis, Cysticercus cellulosae, pigs, Taenia solium.

\section{Introduction}

Porcine cysticercosis caused by Cysticercus cellulosae, a metacestode of zoonotically important cestode parasite Taenia solium, is transmitted to humans through the ingestion of raw or undercooked pork. A more severe manifestation of infection in humans is development of neurocysticercosis (NCC) [1-3]. Pigs acquire infection through consumption of human faeces, or through feed and drinking water contaminated with $T$. solium ova. In pigs, the cysticerci commonly develop in skeletal muscles, tongue, diaphragm, heart and other organs, including brain and eye $[4,5]$. The infection is endemic in many developing countries of Latin America [6, 7], Africa [8] and Asia [9] and the economic loss resulting from condemnation of infected pork is substantially high [5, 10-12]. Specific diagnosis of porcine cysticercosis is critical for identification of endemic regions and for development of strategies to control the infection [13]. Further, prevalence of porcine cysticercosis is suggestive of an active transmission of the parasite between pigs and humans [14]. Though prevalence of cysticercosis has been reported from several parts of India, information from the Bareilly region is scanty.

Therefore, the present work was undertaken to study the level of prevalence of porcine cysticercosis in Bareilly region of northern India.

Copyright: The authors. This article is an open access article licensed under the terms of the Creative Commons Attribution License (http://creativecommons.org/licenses/by/2.0) which permits unrestricted use, distribution and reproduction in any medium, provided the work is properly cited.

\section{Materials and Methods}

Study area: The investigation was carried out in local makeshift slaughter houses of Bareilly District, located in the state of Uttar Pradesh in the northern part of India. Bareilly District is located between latitude $28^{\circ}$ and longitude $78^{\circ}$ and $79^{\circ} 47^{\prime}$ east. The climate is hot, humid and subtropical, however, during winters the temperature deeps to 2 to $15^{\circ} \mathrm{C}$. The annual rainfall is around 500-700 $\mathrm{mm}$.

Postmortem inspection: Two local makeshift slaughter houses were visited once in a week, during August, 2012 to July, 2013. The slaughtered pigs were systematically examined for C. cellulosae through deep incision into several organs, viz., the tongue, masseter muscles, myocardium, thigh muscles, and liver [15].

Collection and processing of samples: 175 pigs, slaughtered at Bareilly region, were screened for $T$. solium cysticerci. The measly pork was brought to laboratory on ice and processed immediately. The cysts were dissected out aseptically from the muscles and were fixed in 10\% alcohol formal acetic acid (AFA) solution and stained with Borax carmine.

Statistical analysis: The data were analyzed by oneway ANOVA test using the SPSS version 16 (SAS USA) and results were expressed as Mean \pm SD.

\section{Results}

Based on characteristic morphological features of the scolex of four suckers and a rostellum bearing 25- 
Table-1: Prevalence (\%) of porcine Cysticercus cellulosae based on sex, age and breed wise in Bareilly, Northern India.

\begin{tabular}{|c|c|c|c|c|c|c|c|}
\hline \multirow[t]{2}{*}{ Parameters } & \multicolumn{2}{|c|}{ Sex } & \multicolumn{2}{|c|}{ Age } & \multicolumn{2}{|c|}{ Breed } & \multirow[t]{2}{*}{ Total } \\
\hline & Male & Female & $1-12$ months & 13-24 months & $\begin{array}{l}\text { Non-descriptive/ } \\
\text { Local breed }\end{array}$ & Cross breed & \\
\hline $\begin{array}{l}\text { No. of samples collected } \\
\text { Positive samples }\end{array}$ & $\begin{array}{c}83 \\
4\end{array}$ & $\begin{array}{c}92 \\
5\end{array}$ & $\begin{array}{c}131 \\
7\end{array}$ & $\begin{array}{c}44 \\
2\end{array}$ & $\begin{array}{c}73 \\
3\end{array}$ & $\begin{array}{c}102 \\
6\end{array}$ & $\begin{array}{c}175 \\
9\end{array}$ \\
\hline Prevalence $\%$ & $4.82^{\mathrm{a}} \pm 0.97$ & $5.43^{\mathrm{a}} \pm 0.96$ & $5.34^{\mathrm{a}} \pm 0.54$ & $4.55^{\mathrm{a}} \pm 2.54$ & $4.11^{\mathrm{a}} \pm 1.05$ & $5.88^{\mathrm{a}} \pm 1.11$ & 5.14 \\
\hline
\end{tabular}

Superscript 'a' indicates that values did not show any significant difference $(P<0.05)$

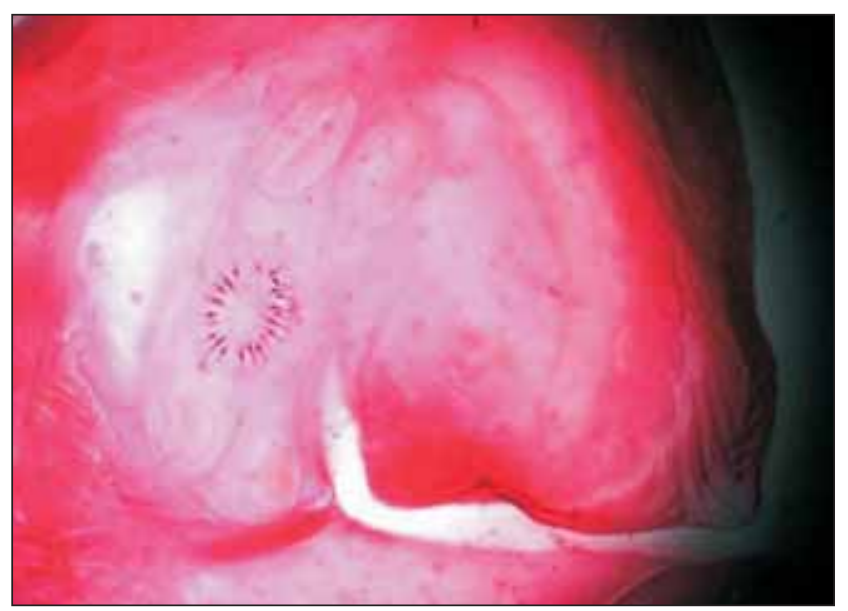

Figure-1: Scolex of Taenia solium cysticercus showing suckers and rostellum bearing two rows of hooks.

28 hooks in two rows, 9 pigs were found positive for $C$. cellulosae from a total of 175 pig carcasses examined $(5.14 \%)$ (Figure-1). Sex-wise prevalence of infection was recorded as $4.82 \%(4 / 83)$ in male and $5.43 \%(5 / 92)$ in female pigs, respectively (Table-1). The prevalence of infection was higher in the age group of 1-12 months (5.34\%) in comparison to the older stocks of 13-24 months of age group (4.54\%) (Table-1). However, there was no significant difference in the prevalence of cysticercosis between the sexes of pigs when all animals were included in the analysis. Cross bred pigs showed marginally higher prevalence of $5.88 \%(6 / 102)$ than the non-descriptive local pigs $4.11 \%(3 / 73)$ (Table-1).

\section{Discussion}

The present study was undertaken to record the prevalence of C. cellulosae in pigs in Bareilly district of Uttar Pradesh from August, 2012 to July, 2013. An overall prevalence of porcine cysticercosis was recorded as $5.14 \%$. According to the previous reports based on post-mortem examination of pigs occurrence of porcine cysticercosis from Uttar Pradesh was recorded as 2.53 to $9.3 \%$. [16, 17$]$.

Prasad et al. [18] documented a high frequency of cysticercosis (26\%) in swine from Mohanlalganj block of Lucknow district in the State of Uttar Pradesh and $40 \%$ of infected pigs had cysticerci located in the brain. Prakash et al. [19] studied the occurrence of neurocysticercosis (NCC) in pigs slaughtered at a local abattoir of Bareilly between August, 2005 to March, 2006 and reported the prevalence of NCC in 3\% $(6 / 200)$ of the pigs by gross and histopathological examination. The result of the present study is in agreement with that of these workers. Though, it is not in agreement with the findings of Prasad et al. [18], the study confirms that Bareilly region is endemic for porcine cysticercosis.

Comparatively higher prevalence of porcine cysticercosis (5.34\%) in the age group of 1-12 months may not ascribe a scientific basis of higher infectivity in young stocks, but it may be due to the fact that more animals in this age group are slaughtered for consumers' preference and therefore contributed higher in the prevalence data when compared to a slightly low (4.54\%) occurrence in 13-24 months of age group. Higher prevalence of porcine cysticercosis in piglets was reported earlier from India [20]. Young piglets of 2-4 weeks of age were associated with spread of infection in rural community of Mexico [21].

A marginally higher prevalence of porcine cysticercosis in females $(5.43 \%)$ recorded in the present study is in agreement with the earlier reports [20-22]. Since the female animals are reared for longer period to increase the herd size, female pigs have higher possibility of acquiring infection from the contaminated field. Further the natural feeding behaviour of pigs along with the litters around human habitats increases the chance of picking infection [20,21].

The finding of prevalence of porcine cysticercosis more in cross bred animals $(5.88 \%)$ than nondescript local breeds $(4.10 \%)$ (Table- 3 ) is in agreement with that of Deka and Gaur [23]. However, it may be premature to conclude that non descriptive local breeds may be more resistant to cysticercosis than their crossbreds counterparts found in this region. The finding supports the similar findings of Phiri et al. [24] and Sikasunge et al. [25]. 


\section{Conclusions and Recommendations}

Cysticercosis is a preventable zoonosis responsible for a significant number of human epilepsy cases in most developing countries, especially in India where neurocysticercosis is an important emerging disease of the central nervous system, second to tuberculosis infection. Further spread of the infection can be controlled by standard meat inspection protocols, proper sanitary measures, and proper disposal of garbages to ensure public health and by awareness on the zoonotic importance of the disease [26]. Further, control of porcine cysticercosis is an achievable target by following good agricultural practices, integrated control programme and adequate hygiene in piggeries.

\section{Authors' contributions}

BCS and AKT designed the work, HVM and BCS carried out the work, SCG helped in manuscript preparation. KK and PT collected materials for manuscript and revised the manuscript. NRS collected samples. All authors read and approved the final manuscript.

\section{Acknowledgments}

The authors are thankful to the Director, Indian Veterinary Research Institute, Izatnagar for the facilities provided. The work was carried out using the institute fund provided for the project approved by The Director and The Joint Director (Research), Indian veterinary Research Institute.

\section{Competing interests}

The authors declare that they have no competing interests.

\section{References}

1. Ocana, G. S., Sablon, J. C. O., Tamayo, I.O., Arena, L. A., Ocana, L.M. S. and Govender, S. (2009) Neurocysticercosis in patients presenting with epilepsy at St Elizabeth's Hospital, Lusikisikis, Afr Med J, 99: 588-591.

2. Singh, G. and Sappal, M. (2012) Neurocysticercosis - Indian scenario. Medicine Update, 22:29-36.

3. Rottbeck, R., Nshimiyimana, J. F., Tugirimana, P., Dü11, U. E., Sattler, J., Hategekimana, J. C., Hitayezu, J., Bruckmaier, I., Borchert, M., Gahutu, J.B., Dieckmann, S., Harms, G., Mockenhaupt, F. P. and Ignatius, R. (2013) High Prevalence of Cysticercosis in People with Epilepsy in Souther Rwanda, PLoS Negl Trop Dis, 7(11): 1-10.

4. Kumar, D. and Gaur, S.N.S. (1994) Taenia solium cysticercosis in pigs. Helminthological Abstracts, CAB, 63: 365-383.

5. Flisser, A., Rodriguez, C. R. and Willingham. A. L. (2006) Control of 292 taeniosis/cysticercosis complex, future developments, Vet Parasitol, 139: 283-292.

6. Eshitera, E. E., Githigia, S. M., Kitala, P., Thomas, L. F., Fevre, E. M., Harrison, L. J. S., Mwihia, E. W., Otieno, O. R., Ojiambo, F. and Maingi, N. (2012) Prevalence of porcine cysticercosis and associated risk factors in Homa Bay District, Kenya, BMC Vet Res, 8:234.

7. Flisser, A. (2002) Epidemiological studies of taeniosis and cysticercosis in Latin America. In: Craig P, Pawlowski Z, eds. Cestode Zoonoses: Echinococcosis and Cysticercosis an Emergent and Global Problem, Amsterdam, IOS Press, 3: $3-12$.

8. Geerts, S., Zoli, A., Willingham, L., Brandt, J and Dorny, P.
(2002) Taenia solium cysticercosis in Africa: an under recognised problem. In: Craig P, Pawlowski Z, eds. Cestode zoonoses: echinococcosis and cysticercosis An emergent and global problem, Amsterdam: IOS Press, 13-23.

9. Ito, A., Sako, Y., Nakao, M. and Nakaya, K. (2002) Neurocysticercosis in Asia: serology/seroepidemiology in humans and pigs. In: Craig, P., Pawlowski Z, (eds). Cestode Zoonoses: echinococcosis and cysticercosis, an emergent and global problem. Amsterdam: IOS Press, pp. 25-32.

10. Pawlowski, Z., Allan, J and Sart, E. (2005) Control of Taenia solium taeniasis/cysticercosis: From research towards implementation, Int J Parasitol, 35: 1221-1232.

11. Tiwari, P M., Chikweto, A., Belot, G., Vanpee, G., Deallie, C., Stratton, G and Sharma, R.N.(2009) Prevalence of intestinal parasites in pigs in Grenada, West Indies, West Indian Vet J, 9(1): 22-27.

12. Deckers, N. and Dorny, P. (2010) Immunodiognosis of Taenia solium taeniosis/cysticercosis: review, Tren Parasitol, 26: 137-144.

13. Gonzalez, A.E., Gavidia, C., Falcon, N., Bernal, T., Verastegui, M., Garcia, H.H., Gilman, R.H., Tsang, V.C. and cysticercosis working group in Peru. (2001) Protection of pigs with cysticercosis from further infections after treatment with oxfendazole, Am J Trop Med Hyg, 65: 15-18.

14. Mohan, V. R., Tharmalingam, J., Muliyil, J., Oommen, A., Dorny, P., Vercruysse, J. and Vedantam, R.(2012) Prevalence of porcine cysticercosis in Vellore, South India, Trans R Soc Trop Med Hyg, 107(1): 62-64.

15. Thornton, H, Gracey, J.F. (1974) Textbook of Meat Hygiene. 6 Edition. Bailliere and Tindall, London. p341-3454.

16. Varma, T. K. and Ahluwalia, S. S. (1981) Potential danger of cysticercosis and taeniasis in man and animals. Livestock Advisor, 6: 54-56.

17. Pathak, K. M. L., Gaur, S. N. S. and Garg, S. K. (1984) Counter current immuno-electrophoresis, a new technique for rapid serodiagnosis of porcine cysticercosis. J Helminthol, 58:321-324.

18. Prasad, K. N., Chawla, S., Jain, D., Pandey, C. M., Pal L., Pradhan, S. and Gupta, R. K. (2002) Human and porcine Taenia solium infection in rural north India. Trans $R$ Soc Trop Med Hyg, 96: 515-516.

19. Prakash, A., Sai Kumar, G., Rout, M., Nagarajan, K. and Kumar, M. (2007) Neurocysticercosis in free roaming pigs a slaughter house survey, Trop Anim Health Prod, 39: 391394.

20. Borkataki, S., Islam, S., Borkakati M.R., Goswami, P. and Deka, D.K. (2012) Prevalence of porcine cysticercosis in Assam, India, Vet World, 5 (2): 86-90.

21. Aluja, A.S. de Martinez, J. J and Villalobos, A.N.M. (1998) Tania solium cysticercosis in young pigs: age at first infection and histological characteristics, Vet Parasitol, 76 : 71-79.

22. DevSarma, M. K. (1999) Some aspects of hydatidosis and other common larval cestodes of domestic animals. M.V.Sc. Thesis submitted to A.A.U., Guwahati-22, Assam.

23. Deka, D.K. and Gaur, S.N.S. (1990). Tania solium cysticercosis in pigs in western parts of Uttar Pradesh. J Vet Parasitol, 4(1): 59-63.

24. Phiri, I.K., Dorny, P., Gabriel, S., Willingham 3rd, A.L., Sikasunge, C., Siziya, S., Vercruysse, J. (2006) Assessment of routine inspection methods for porcine cysticercosis in Zambian village pigs. J Helminthol, 80: 69-72.

25. Sikasunge, C.S., Phiri, I.K., Phiri, A.M., Siziya,S., Dorny, P., Willingham, A.L. (2008) Prevalence of Taenia solium porcine cysticercosis in the Eastern, Southern and Western provinces of Zambia. Vet J, 176: 240-244.

26. Alexander, A. M., Mohan, V. R., Muliy, J., Dorny, P. and Rajshekhar, V. (2012) Changes in knowledge and practices related to taeniasis /cysticercosis after health education in a south Indian community, Int Health, 4(3):164-169. 